\title{
Researching Resilience in Bachelor of Science in Nursing (BScN) Students
}

\author{
Greg Anderson \\ Justice Institute of \\ British Columbia
}

\author{
Meridy Black \\ Vancouver \\ Community College
}

\author{
John Collins \\ Vancouver \\ Community College
}

\author{
Adam Vaughan \\ Justice Institute of \\ British Columbia
}

\begin{abstract}
Resilience is a significant focus regarding the mental health of public health service workers in Canada. It is also a centre of attention in current nursing research worldwide. Included in this are a broad range of definitions, experiences and approaches to the research itself and to supporting the development of resilience in nurses and nursing students.

The authors of this paper embarked on a research study aimed at testing an intervention designed to enhance the resilience and coping skills of students in the BScN program at Vancouver Community College (VCC). It had been observed, anecdotally, by program faculty that students of the program were demonstrating higher rates of stress and less effective coping skills from one cohort to the next. The 'intervention' takes the form of a self-paced, online resiliency program that had previously been tested among frontline responders and found to be effective [1]. VCC's Nursing Department formed a research partnership with the authors at the Justice Institute of British Columbia (JIBC) to carry out a similar study. The study is being conducted using a quasiexperimental design which examines students responses before and after exposure to clinical practice areas. This paper relates the issues that underpin the need for this research, including the significance of studying resilience and coping skills in nursing students. After highlighting the general and specific contexts for the study of resilience, we discuss the importance of the study findings to developing curriculum that can support evidence-informed teaching for resilience and coping skills in the BScN program.
\end{abstract}

\section{Introduction}

Vancouver Community College is a postsecondary education institution based in Vancouver, British Columbia. The nursing department at Vancouver Community College offers a number of nursing and health care programs, including the $\mathrm{BScN}$. The program has an intake of two cohorts per year. Students in the the first cohort are generic entry students (starting from Term 1) and the second cohort are licensed practical nurses (LPNs) who receive advanced placement in the BScN (starting from Term 4), as they seek to convert to registered nurses. Anecdotal evidence from faculty suggested that, over time, students entering the program appeared to be more stressed and were equipped with less effective coping skills and strategies to deal with the academic rigors of a BScN program. Students, themselves, identified high levels of stress at various junctures in the program. In addition, the authors are aware, through their work in mental health, of an increasing incidence of post-traumatic stress disorder (PTSD) and post-traumatic stress injury (PTSI) in society in general, as well as in public service occupations particularly. [2]

With general statistics indicating that one in four Canadians cite stress as their reason for leaving their job [3] (and retention of new graduates is something that nursing struggles with), $73 \%$ of all adults, aged 20 to 64 , also report experiencing some level of stress in their daily lives. [4] College students in Canada report stress (42\%), anxiety (32.5\%) and sleep difficulties (28.4\%), among other factors, significantly affecting their academic performance in a 12-month period. [5] In this context, it is, perhaps, less surprising to hear claims that, by age 40, 1 in 2 Canadian adults will have, or have had, a mental illness. [6] Against this background, one might expect that the resilience of $\mathrm{BScN}$ students, as members of society, will be impacted in a similar fashion to the general public.

When researchers at the Justice Institute of British Columbia (JIBC) presented the opportunity to participate in a follow-up study to their 2017 study with paramedics, the timing was mutually beneficial to both post-secondary institutions and the students of the $\mathrm{BScN}$ program.

\section{Resilience in the Public Health and Safety Professions}

The first comprehensive nationwide study in Canada of Public Health and Safety Personnel (PHSP) evidenced that $44.5 \%$ screened positive for at least one mental health disorder (e.g. anxiety, depression, 
suicidal ideation, post-traumatic stress disorder) as a consequence of their work in a trauma-exposed profession. [7] Further, Tema Conter Memorial Trust reported over 145 PHSP died by suicide in Canada between 2015 and 2017 [8]. The Canadian Government, concurrently, developed a national action plan and presumptive legislation that increased support for PHSP coping with occupational stress injuries. This support is now in place in most provinces. Part of the Ministerial Roundtable's "Key Takeaways" underscored the importance of resilience, treatment and reintegration into the workplace for PHSP. Roundtable participants also agreed that "evidence-based research is required to ensure that the right steps and programs are being implemented". [7] This conclusion underlines the need for researched interventions which are demonstrated to be effective in supporting and extending resilience in workers in the health and safety professions.

\section{Resilience in Nursing}

Nursing is a healthcare profession where resilience and coping skills are a focus of concern. Since the mid to late 1980 s, nurse researchers and educators have been placing an ever-increasing emphasis on these concepts in their work. [9] A preliminary review of the extant literature in nursing produced a significant number of articles addressing the issue of resilience among practicing nurses, as well as studies undertaken with undergraduate nursing students. [9][10][11] The review also reveals wide variation in the definition of resilience across research studies. For example, Delgado et al. report that resilience manifests as a personal ability that enables the nurse to face the challenges of adversity within their workload. [12] Mealer et al. identify resilience as "bouncing back" following exposure to circumstances that are stressful. [13] Shimoinaba et al. add the connection of resilience to coping in the context of loss and adversity; both major components of nursing work. [14] Thomas and Asselin claim that resilience is more than overcoming challenging circumstances and postulate that it leads to fostering learning and capacity from the contextual experience. [15] In the study the authors are undertaking, the definition of resilience is embedded in the valid metrics of the 'Resilience Scale for Adults' [16] and 'Coping Strategy Indicators' [17] scales.

Notwithstanding the lack of a common definition in the literature, or even in the broader field of social science and humanities research, studies have consistently addressed two main areas where intervention might have a significant impact on the resilience of nurses.

The first area is highly complex and involves intervention at the systemic level. "Undoubtedly, there is a need to improve organizational approaches to workplace adversity and systemic environmental problems that persist in the nursing...workplace". [11] While it is acknowledged that serious intervention is merited at this level, it will take time to uncover the factors involved, to enact the necessary interventions and for those interventions to have their effect. This area of intervention is the subject of ongoing and incremental effort.

In the interim, there is a need to provide support to the individual nurses who work in those systems (the second area for intervention) and to find effective interventions to increase their personal resilience and coping skills. The reason resilience has become a growing issue for nursing in recent years is because nurses are faced with the challenges of continuously changing environments and contexts of care. Hart et al. have highlighted issues around nursing shortages, higher acuity in patients, advanced technologies in use in most areas of practice, ever-evolving regulatory requirements, and the physical and psychological demands of the work and the workplace as factors that threaten the physical and psychological wellbeing of nurses. [18] These factors are associated with an increase in negative consequences for nurses. "Workplace adversity is the cluster of negative occupational conditions, situations or events that cause hardship, stress and burnout." [11] It is to this environment that new graduate nurses are introduced when they take up their first employment. New graduate nurses are repetitively described in the literature as experiencing "reality shock". [10][11] This often leads to emotional exhaustion in their first year of practice. In the light of this evidence, it is no surprise then that estimates suggest that up to sixty percent of new graduates will leave their first position in the first year of practice. [9][12] This situation underlines the need to start addressing resilience and coping skills in undergraduate nursing education programs. Even there, student nurses are subject to traumatic and stressful events, in the rigour of classroom studies, and exposure to the factors discussed above while attending clinical practice experiences during their program of studies.

In their extensive review of the literature, Thomas and Asselin noted that resilience has been correlated with decreased incidence of post-traumatic stress disorder, anxiety, depression, stress and symptoms of burnout. [15] Education to promote resilience and build coping skills is also correlated with these reductions on the negative impacts of practice. [9][19]

The authors of this paper are curious as to whether and how increased resilience and coping skills can be instilled or drawn out in nursing students, and, if they can, whether those skills decay over time and into post-graduate practice? These questions address the second level of intervention identified in the literature and are the focus of the research that the authors are engaged in.

In Canada, several studies have demonstrated that nurses, in particular, are at high risk of developing 
stress-related mental health problems as a result of their work and the specific challenges that they face. [20][21] A recent publication of the Canadian Federation of Nurses Unions [22] reported that $61 \%$ of nurses have experienced abuse, harassment, or assault in the workplace. In 2015, the British Columbia Nurses Union (BCNU) reported that nurses are working in unsafe conditions and are faced with impossible workloads. Furthermore, out of 34 occupations, nurses lose the most work days nationwide due to workplace violence. [23] The stressful environment nurses work in is accentuated in B.C. where nursing professions are listed in the top 5 occupations for injuries between 2006-2015. [24] Nursing professionals have also received media attention at the time of their exclusion from recent amendments, in some provinces, to workers' compensation presumptive legislation that facilitates better access to coverage for Public Health and Safety Personnel suffering from PTSD. Fortunately, progress has been made on this front since the media focused on it.

\section{Building Resilience in $\mathrm{BScN}$ Students}

The literature which addresses resilience in nursing students focuses on the nature of the clinical environment and the experiences of students entering each of these environments for the first time throughout their program of studies. "Patient care places them in many "first" situations that may cause anxiety or discomfort, including the intimate care of both male and female patients, death and dying, diverse lifestyles, exposure to communicable diseases etc.”. [9] The literature also points to nurse educators as being in prime position to assist students in developing resilience and coping skills. In fact, education is one of the most commonly cited interventions in the nursing research literature with regard to developing a number of facets of resilience in undergraduate students. Resilience training has previously been found to increase resilience and decrease symptoms of depression and post-traumatic stress disorder (among other symptoms) in nurses and student nurses. [9][15]

\section{Research Method}

The authors have set out to test an education intervention which has already demonstrated some efficacy in primary care paramedic students. Anderson et al. developed the Online Resilience Resource (ORR) in conjunction with PHSP with lived experience, and with input from health professionals (e.g. psychologists, social workers). [1] This same tool (with obvious minor edits) is being applied as the intervention in the study with BScN students. In the study cohort are students with none to very little previous exposure to nursing environments (Generic) and Licensed Practical Nurses with 2 or more years of post-graduate practice experience (Advanced).

The ORR represents the intervention in this quasiexperiment, with participants completing questionnaires before and after the intervention. The participants complete the first round of questionnaires followed by the ORR prior to their clinical experience in the associated term of the program (e.g. acute care, medical and surgical, long-term care, children's nursing, mental health). After completing the ORR, they repeat the resilience questionnaire before heading out to the clinical practice experience. The questionnaires are administered once more, immediately after the clinical experience. These validated tools (the questionnaires), and the analysis of the data collected, will be reported, in full, on completion of the study, at the end of 2019.

Preliminary results of the study are showing a tendency towards increased resilience in the $\mathrm{BScN}$ students following completion of the ORR. Once all of the data is collected and analyzed, we will be in a position to report whether this trend is confirmed and, if so, if it constitutes a statistically significant change from the baseline measurements.

\section{Adding to our understanding of Resilience in BScN Students}

While this quantitative study presents the opportunity to gain meaningful and useful insights into $\mathrm{BScN}$ students' resilience and coping skills, the authors plan to add to the potency of this data through the addition of further data, collected from a second study. The use of mixed methods research offers a means to strengthen the rigor of the findings and gives the participants a voice in the process. It is proposed that the second study be conducted during 2020-21, with reporting by the end of 2021 .

\section{Discussion}

Faculty, teaching in the VCC BScN Program, believe that there is a pressing need to develop resilience and provide coping skills to $\mathrm{BScN}$ students from an early point in their program of studies. With the continuing nursing shortage in Canada, and the increasing average age of nurses in practice, the need for new RNs is critical to effective manpower planning and service provision in healthcare. While the transition to baccalaureate level learning challenges most students entering the program, laboratory and clinical practice experiences engage them in real-life environments which present many of the same situations encountered by Registered Nurses. Added to this are the stresses of 'modern living' for students, which include financial struggles and hardship, accommodation issues (Vancouver is the most expensive city to live in, in Canada!), 
existing mental health conditions, dependents - older adults and children, peer pressure, and a lack of or limited support networks. All of these factors, and more, mean that students are studying in a high stress environment. At the same time, they must acquire the RN entry-to-practice competencies during the program, an area where faculty cannot compromise.

The nursing curriculum needs to take account of student vulnerability and, at the same time, build resilience throughout the program. If the ORR proves effective in building resilience and coping skills in students in the study, then this can easily be provided to students through VCC's online learning centre.

Because the preliminary results suggest that the on-line resiliency training tool has yielded positive responses from pre to post test, a follow-up qualitative study, as proposed, with participation offered to some of the same student groups has the potential to uncover how the ORR specifically helped with the students' ability to deal with stress in the learning environment. This study can also provide indicators of how students used (or did not use) resilience and coping skills, addressed in the ORR, in a clinical learning context.

\section{Conclusion}

The initial quantitative research study, discussed in this article, is a work in progress, which we anticipate completing in the fall of 2019. At the time of the Canada International Conference on Education (CICE 2019), in addition to the content in this paper, the authors were able to present some preliminary data from the study. This work has implications, not just for health care personnel, but for the public in general, given the increasing issues with stress and mental health in society. From the evidence already available in the nursing research literature and cited in this paper, education interventions form a key contribution (albeit one of several identified) to the development of individual resilience and coping skills in undergraduate nursing students. In the long-term, the aim of this study is to evaluate the resource (ORR), determine its efficacy, and then, pending positive evidence, to make it freely available to all Public Health and Safety Personnel.

\section{References}

[1] G. S. Anderson, A. D. Vaughan, and S. Mills, "Building personal resilience in paramedic students", Journal of Community Safety \& Well-Being, 2(2), SG Publishing Inc., Saskatoon, SK, 2017, pp. 51-54.

[2] R. N. Carleton, T. O. Afifi, S. Turner, T. Taillieu, S. Duranceau, D. M. LeBouthillier, . . . G. J. G. Asmundson, "Mental disorder symptoms among public safety personnel in Canada", The Canadian Journal of Psychiatry / La Revue canadienne de psychiatrie, 63(1), Canadian Psychiatric Association, Ottawa, ON, 2018, pp. 54-64.
[3] Global News, "This is the state of stress 2018", April 26 2018, Retrieved from https://globalnews.ca/news/ 4138006/stress-causes-today/

[4] Statistics Canada, Perceived Life Stress, 2014, Retrieved from https://www150.statcan.gc.ca/n1/ pub/82-625-x/2015001/article/14188-eng.htm

[5] American College Health Association, American College Health Association-National College Health Assessment II: Canadian Reference Group Executive Summary Spring 2016, 2016, Retrieved from https://www.acha.org/documents/ncha/NCHAII\%20SPRING\%202016\%20CANADIAN\%20REFEREN CE\%20GROUP\%20EXECUTIVE\%20SUMMARY.pdf

[6] P. Smetanin, D. Stiff, C. Briante, C. E. Adair, S. Ahmad, and M. Khan, The Life and Economic Impact of Major Mental Illnesses in Canada: 2011 to 2041. RiskAnalytica, on behalf of the Mental Health Commission of Canada, Toronto, ON, 2011.

[7] Public Safety Canada, Ministerial Roundtable on PostTraumatic Stress Disorder in Public Safety Officers, 2016, Retrieved from https://www.publicsafety.gc.ca/cnt/rsrcs/pblctns/mnstrlrndtbl-ptsd/mnstrl-rndtbl-ptsd-en.pdf

[8] K. Engqvist, "Front-line stress and trauma: are Island first responders prepared?" Sooke News Mirror, April 28 2018, Retrieved from https://www.sookenewsmirror.com/news/front-line-stressand-trauma-are-island-first-responders-prepared/

[9] T. M. Stephens, "Nursing student resilience: a concept clarification", In Nursing forum, 48(2), Wiley-Blackwell, Hoboken, NJ, 2013, pp. 125-133.

[10] C.A. DuBois and J.F.Z. Gonzalez, "Implementing a resilience-promoting education program for new nursing graduates", Journal for Nurses in Professional Development, 34(5), Wolters Kluwer Health, Philadelphia, PA, 2018, pp. 263-269.

[11] G. McDonald, D. Jackson, L. Wilkes, and M. H. Vickers, "A work-based educational intervention to support the development of personal resilience in nurses and midwives", Nurse Education Today, 32, Elsevier, Amsterdam, NL, 2012, pp. 378-384.

[12] C. Delgado, D. Upton, K. Ranse, T. Furness, and K. Foster, "Nurses' resilience and emotional labour of nursing work: An integrative review of empirical literature", International Journal of Nursing Studies, 70, Elsevier, Amsterdam, NL, 2017, pp. 71-88.

[13] M. Mealer, R. Hodapp, D. Conrad, S. Dimidjian, B. Rothbaum, and M. Moss, "Designing a Resilience Program for Critical Care Nurses", Advanced Critical Care, 28(4), The American Association of Critical Care Nurses, Aliso Viejo, CA, 2017, pp. 359-365.

[14] K. Shimoinaba, M. O'Connor, S. Lee, and D. Kissane, "Nurses' resilience and nurturance of the self", International Journal of Palliative Nursing, 21(10), Mark Allen Group, London, UK, 2015, pp. 504-510. 
[15] L.J. Thomas and M. Asselin, "Promoting resilience among nursing students in clinical education", Nurse Education in Practice, 28, Elsevier, Amsterdam, NL, 2018, pp. 231-234.

[16] O. Friborg, D. Barlaug, M. Martinussen, J.H. Rosenvinge, O. Hjemdal. "Resilience in relation to personality and intelligence", International Journal of Methods in Psychiatric Research 14(1), John Wiley \& Sons, Hoboken, NJ, pp. 29-42.

[17] J. H. Amirkhan, "A factor analytically derived measure of coping: The Coping Strategy Indicator", Journal of Personality and Social Psychology, 59(5), The American Psychological Association, Washington, DC, 1990, pp. 1066-1074.

[18] P. L. Hart, J. D. Brannan, \& M. De Chesnay, "Resilience in nurses: An integrative review", Journal of Nursing Management, 22(6), Wiley-Blackwell, Hoboken, NJ, 2015, pp. 720-734.

[19] S. Chesak, A. Bhagra, D. R. Schroeder, D. A. Foy, S.

M. Cutshall, and A. Sood, "Enhancing resilience among new nurses: Feasibility and efficacy of a pilot intervention", The Ochsner Journal, 15(1), Ochsner Clinic Foundation, Jefferson, LA, 2015, pp. 38-44.

[20] H. K. Spence Laschinger, and A. Nosko, "Exposure to workplace bullying and post-traumatic stress disorder symptomology: the role of protective psychological resources", Journal of Nursing Management, 23(2), WileyBlackwell, Hoboken, NJ, 2015, pp. 252-262.

[21] M. Shields and K. Wilkins, National survey of the work and health of nurses 2005: Provincial profiles. Statistics Canada, Ottawa, ON, 2006.

[22] The Canadian Federation of Nurses Unions, Enough is enough; putting a stop to violence in the health care sector, 2017, Retrieved from http://nursesunions.ca/wp-content/ uploads/2017/05/CFNU_Enough-is-Enough_June1_ FINALlow.pdf

[23] Association of Workers' Compensation Boards of Canada, National work injury, disease, and fatality statistics, 2018.

[24] WorkSafeBC, Statistics 2015, 2015, Retrieved from https://www.worksafebc.com/en/resources/about-us/ annual-report-statistics/2015-stats?lang=en

\section{Acknowledgements}

The authors wish to acknowledge funding provided for the research by The President's Research Fund at Vancouver Community College and by WorksafeBC's Innovation at Work Grant. 